NOTA CIENTÍFICA

\title{
ASPECTOS NUTRICIONAIS DE SEMENTES E PLÂNTULAS DE GUAPURUVU DESENVOLVIDAS EM DOIS SUBSTRATOS
}

\author{
NUTRITIONAL ASPECTS OF SEEDS AND PLANTULE OF GUAPURUVU \\ DEVELOPED IN TWO SUBSTRATES
}

\author{
Fernanda SEREDA ${ }^{1}$ \\ Carlos Bruno REISSMANN ${ }^{2}$ \\ Renato MARQUES ${ }^{3}$ \\ Ricardo Miranda de BRITEZ ${ }^{4}$
}

\begin{abstract}
RESUMO
Este trabalho teve como objetivos caracterizar nutricionalmente plântulas de guapuruvu (Schizolobium parahyba (Vellozo) Blake), bem como avaliar as relações entre a composição química das reservas contidas em suas sementes, macronutrientes e micronutrientes, com a sua distribuição na fase de plântulas quando desenvolvidas em dois substratos. $O$ experimento foi conduzido em 2004, em casa de vegetação da UFPR (Curitiba - PR), em um delineamento inteiramente casualizado, com cinco repetições, com os seguintes tratamentos: areia fina e solo do horizonte A do Cambissolo Háplico, da região de origem das sementes. Após o período de sete semanas, procedeu-se a coleta do material separando-os em parte aérea, cotilédone e raiz. Para obter um valor de referência das reservas totais das sementes, partindo do princípio de que essa seja a principal fonte nutricional utilizada durante a germinação e fase de plântula, fez-se a análise química dos cotilédones. Esses valores foram comparados com o somatório dos compartimentos obtidos no experimento em casa de vegetação. Em ambos os casos o material, após seco e moído, foi analisado quimicamente para as variáveis $\mathrm{N}, \mathrm{P}, \mathrm{K}, \mathrm{Ca}, \mathrm{Mg}$, $\mathrm{Fe}, \mathrm{Mn}, \mathrm{Cu}$ e Zn. Os resultados indicaram que plântulas desenvolvidas em solo apresentaram maior produção de massa seca nos compartimentos raiz e parte aérea. Teores de nutrientes de plântulas de guapuruvu em areia fina apresentaram a ordem de $\mathrm{N}>\mathrm{K}>\mathrm{P}>\mathrm{Ca}>\mathrm{Mg}>\mathrm{Fe}>\mathrm{Cu}>\mathrm{Mn}>\mathrm{Zn}$ e em relação ao solo, $\mathrm{N}>\mathrm{K}>\mathrm{Ca}>\mathrm{P}>\mathrm{Mg}>\mathrm{Fe}>\mathrm{Mn}>\mathrm{Cu}>\mathrm{Zn}$. Com relação às reservas das sementes de guapuruvu o conteúdo de $\mathrm{N}$ foi o de maior expressão.
\end{abstract}

Palavras-chave: cotilédone; nutrição mineral; Schizolobium parahyba (Vellozo) Blake.

\section{ABSTRACT}

The study had as objective to characterize the nutritional status plantules of guapuruvu (Schizolobium parahyba (Vellozo) Blake), as well evaluate the relations between the chemical composition of the containing seed reserves, macronutrients and micronutrients, to its distribution in the plantule stage when developed on to substrates. The experiment was conducted in 2004, in UFPR (Curitiba - PR) greenhouse under an entirely randomized design being the two substrates, fine sand and soil from A horizon of an Inceptisol. The soil was collected from the region of the seed source. After a period of seven weeks the plantules were collected and separated into above ground, cotyledons and root parts. To obtain a reference pattern of total seed reserves, considering that these are the main nutritional source utilized during germination and plantules stage, a chemical analysis of the cotyledons was performed. These values were compared to the sum of the compartments obtained from the experiment in the greenhouse. In both cases the sample tissues were dried, grinded and analysed for N, P, K, Ca, Mg, Fe, Mn, Cu and Zn. The results indicated that the plantules developed on the Inceptisol substrate presented higher biomass on roots and above ground components. The nutrient contents of guapuruvu plantules growing on sand substrate presented the following decreasing order: $\mathrm{N}>\mathrm{K}>\mathrm{P}>\mathrm{Ca}>\mathrm{Mg}>\mathrm{Fe}>\mathrm{Cu}>\mathrm{Mn}>\mathrm{Zn}$, while in the soil the content order was $\mathrm{N}>\mathrm{K}>\mathrm{Ca}>\mathrm{P}>\mathrm{Mg}>\mathrm{Fe}>\mathrm{Mn}>\mathrm{Cu}>\mathrm{Zn}$. In relation to the seed reserves of guapuruvu, the content of $\mathrm{N}$ showed to be of highest expression.

Key-words: cotyledon; mineral nutrition; Schizolobium parahyba (Vellozo) Blake.

\footnotetext{
Engenheira Agrônoma, Mestre em Ciências do Solo, Setor de Ciências Agrárias, Universidade Federal do Paraná, Rua dos Funcionários, 1540 , CEP 80035-050, Curitiba, PR. E-mail: fsereda@yahoo.com.br

${ }^{2}$ Engenheiro Florestal, Doutor em Ciências Florestais, Professor Sênior do Departamento de Solos e Engenharia Agrícola da UFPR, Rua dos Funcionários, 1540, CEP 80035-050, Curitiba, PR. E-mail: reissman@ufpr.br

${ }^{3}$ Engenheiro Florestal, Doutor em Ciências Florestais, Professor do Departamento de Solos e Engenharia Agrícola da UFPR, Rua dos Funcionários, 1540, CEP 80035-050, Curitiba, PR. E-mail: marques@ufpr.br

${ }^{4}$ Biólogo, Doutor em Ciências Florestais, Sociedade de Pesquisa em Vida Selvagem e Educação Ambiental, Rua Isaias Bevilacqua, 999 , CEP 80430-040, Curitiba, PR. E-mail: cachoeira@spvs.org.br
} 


\section{INTRODUÇÃO}

Em ambientes naturais, as reservas encontradas em maior proporção na forma de sementes, estão relacionadas com a capacidade de suprir carbono, energia e nutrientes. Um importante composto de reserva chamado fitina tem sido estabelecido como a maior reserva de fósforo e outros nutrientes em muitas sementes. Estes nutrientes são necessários no metabolismo e crescimento do eixo embrionário até que a raiz esteja desenvolvida o suficiente para extraí-los do substrato (LOTT et al., 2000; FERREIRA e BORGHETTI, 2004).

Com o início do processo de degradação dos compostos de reserva, determinados elementos apresentam funções específicas para o futuro desenvolvimento da plântula. O N é constituinte de diversos componentes da célula vegetal, como aminoácidos e ácidos nucleicos. $\mathrm{O} \mathrm{P}$, da mesma forma que o $\mathrm{N}$, é requerido na formação de ácidos nucleicos, além de participar no metabolismo energético das plântulas. $\mathrm{O} \mathrm{K}$ é relevante durante a síntese de proteínas em sementes e manutenção de sua estabilidade (KIGEL e GALILI, 2004; TAIZ e ZEIGER, 2006).

Participam também como constituintes da fitina os macronutrientes secundários $\mathrm{Ca}$ e $\mathrm{Mg}$. Durante a germinação o $\mathrm{P}$ e o Mg migram para diversas partes da plântula, contribuindo para a formação de novos tecidos. Já o $\mathrm{Ca}$, devido à baixa mobilidade, pode forma depósitos denominados de cristais de oxalato em sementes de determinadas espécies, e em muitos casos não sendo mobilizado durante a germinação (LOTT et al., 1982; MENGEL e KIRKBY, 1987)

Com relação aos micronutrientes, o Fe é necessário na formação de componentes do cloroplasto, e geralmente não está localizado nos tecidos do meristema fundamental dos cotilédones. Traços de Mn são especificamente seqüestrados no feixe vascular da radícula, além da sua participação na síntese de clorofila, Reação de Hill e em diversas reações enzimáticas. O $\mathrm{Cu}$ normalmente é encontrado nos cloroplastos na forma de proteínas complexas, como a plastocianina que participam no fluxo de transporte eletrônico durante a fotossíntese (LOTT e SPITZER, 1980; LOTT et al., 1982; MENGEL e KIRKBY, 1987; KIGEL e GALILI, 2004).

Além do acúmulo de substâncias de reserva, há a formação de inúmeros compostos químicos, como os fitormônios. As auxinas ocorrem principalmente na forma de ácido indolacético (AIA), sendo o $\mathrm{Zn}$ seu precursor. O AIA é importante no início do desenvolvimento das sementes, favorece o acúmulo e o armazenamento das reservas da semente e é responsável por atividades de assimilação de compostos da planta-mãe (MENGEL e KIRKBY, 1987; KIGEL e GALILI, 2004).

Aspectos da composição química e da fisiologia das sementes de espécies nativas das florestas tropicais são de enorme relevância para viabilizar o seu uso na recuperação de áreas degradadas. Dentre essas, pode-se citar o guapuruvu (Schizolobium parahyba (Vellozo) Blake), pertencente à família (Caesalpinaceae), espécie utilizada na restauração da Mata Atlântica, e indicada para restauração florestal. Exclusiva da Floresta Atlântica forma grupamentos densos em clareiras, ocupando planícies às margens dos rios e início de encostas (GALVÃO e MEDEIROS, 2002).

O presente trabalho objetivou caracterizar nutricionalmente plântulas de guapuruvu e avaliar as relações entre a composição química das reservas contidas em suas sementes, macronutrientes e micronutrientes, com a sua distribuição na fase de plântulas quando desenvolvidas em dois substratos.

\section{MATERIAL E MÉTODOS}

O trabalho foi realizado em 2004, no Departamento de Solos e Engenharia Agrícola, Setor de Ciências Agrárias, Universidade Federal do Paraná. A coleta das sementes foi feita manualmente após a queda de seus frutos totalmente secos, provenientes de árvores matrizes na reserva da Sociedade de Pesquisa em Vida Selvagem e Educação Ambiental - SPVS, no município de Antonina - PR. Com o objetivo de manter a diversidade genética foram misturadas, formando um lote. $O$ beneficiamento constou na eliminação das sementes mal formadas e posterior limpeza com hipoclorito de sódio a $10 \mathrm{~mL} \mathrm{~L}^{-1}$, seguida da lavagem com água desionizada. O lote foi dividido em duas partes, sendo o primeiro utilizado no experimento em casa de vegetação e, o segundo encaminhado para análise da composição química das reservas nutricionais.

Para o experimento em casa de vegetação, realizou-se a escarificação ao lado do hilo utilizando um esmeril, favorecendo o intumescimento das sementes (AZEVEDO et al., 2003). Os substratos para a germinação das sementes constaram de: (T1) areia fina (fração $<1 \mathrm{~mm}$ ) tratada com ácido clorídrico a $1,5 \mathrm{~mol} \mathrm{~L}^{-1}$, para purificação do material, e posteriormente lavada com água desionizada, para a observação do potencial da espécie em ambiente praticamente inerte e (T2) solo, proveniente de horizonte A de um Cambissolo Háplico (Tabela 1) da região de origem das sementes, sendo esse peneirado em malha de $4 \mathrm{~mm}$. Recipientes plásticos com a capacidade de $500 \mathrm{~mL}$, foram preenchidos com aproximadamente $500 \mathrm{~g}$ de cada substrato, com uma semente por vaso.

O experimento foi conduzido em delineamento inteiramente casualizado, com dois tratamentos (areia fina e solo), e cinco repetições, sendo cada repetição constituída de nove vasos. O experimento foi conduzido até sete semanas, quando ocorreu a eliminação do cotilédone pela plântula, no substrato areia fina, caracterizando que provavelmente ocorreu a exaustão das reservas. Procedeuse então a coleta do material e sua lavagem com água desionizada, separando-o por compartimento da plântula, ou seja, parte aérea, cotilédone e raiz. 
SEREDA, F. et al. Aspectos nutricionais de sementes e plântulas...

TABELA 1 - Análise química do horizonte A do Cambissolo Háplico utilizado como substrato no tratamento T2

\begin{tabular}{ccccccccccccccc}
\hline \multicolumn{11}{c}{ Análise de Solo } \\
\hline $\begin{array}{c}\text { Horizonte A } \\
\text { de }\end{array}$ & $\mathrm{pH} \mathrm{CaCl}_{2}$ & $\mathrm{pH} \mathrm{SMP}$ & $-\mathrm{Al}^{-}$ & $\mathrm{H}+\mathrm{Al}$ & $\mathrm{Ca}$ & $\mathrm{Mg}$ & $\mathrm{K}$ & $\mathrm{P}$ & $\mathrm{C}$ & $\mathrm{Fe}$ & $\mathrm{Mn}$ & $\mathrm{Cu}$ & $\mathrm{Zn}$ \\
$\begin{array}{c}\text { Cambissolo } \\
\text { Háplico }\end{array}$ & 4,50 & 5,60 & 0,30 & 6,70 & 3,45 & 1,03 & 0,10 & 28,20 & 23,80 & 98,20 & 22,28 & 2,24 & 3,32 \\
\hline
\end{tabular}

Partindo do princípio de que durante a germinação e fase de plântula, as sementes têm como única fonte nutricional a semente (FERREIRA e BORGHETTI, 2004), realizou-se a análise química dos macronutrientes e micronutrientes. As análises da composição química das sementes constaram de cinco repetições, sendo cada constituída de vinte sementes. Esses valores serviram como referência das reservas iniciais da semente utilizadas pelas plântulas, constituindo um terceiro tratamento. Sendo comparado com o somatório dos compartimentos, parte aérea, cotilédone e raiz nos substratos areia fina e solo. Esse tratamento teve como objetivo estimar a contribuição da semente para o desenvolvimento das plântulas durante o período em casa de vegetação.

Em ambos os casos o material, após seco, foi determinada a massa, moído e analisado quimicamente para as variáveis $\mathrm{N}, \mathrm{P}, \mathrm{K}, \mathrm{Ca}, \mathrm{Mg}, \mathrm{Fe}$, Mn, Cu e Zn (MARTINS e REISSMANN, 2007).

Com base nas análises e medições, calcularam-se os seguintes parâmetros: concentração e conteúdo de nutrientes para os compartimentos das plântulas e reservas das sementes. Os valores encontrados foram avaliados pela análise de variância, e as médias comparadas pelo teste de Tukey a $5 \%$ de probabilidade.

\section{RESULTADOS E DISCUSSÃO}

As plântulas cultivadas no solo, alcançaram valores estatisticamente superiores para a produção de massa seca ao final do experimento, com exceção do compartimento cotilédone, no qual os valores não diferiram estatisticamente entre si pelo teste de Tukey ao nível de $5 \%$ de probabilidade (Tabela 2). A maior acumulação de massa seca pode ser explicada devido a maior oferta de nutrientes do substrato solo (Tabela 1) quando comparado a areia fina. As plântulas, no substrato areia fina, se utilizando principalmente das reservas nutricionais da semente, obtiveram maior relação raiz/parte aérea $(0,7761)$ do que no substrato solo $(0,4987)$. Segundo BRAGA et al. (1995) plantas em ambientes oligotróficos apresentam maior relação raiz/parte aérea como estratégia para retirar o máximo de nutrientes dessa situação. O mesmo pode ser observado nos estudos de STASOVSKI e PETERSON (1991) e NICOLOSO et al. (1999), em condições oligotróficas, que constataram maior investimento radicular pelas espécies estudadas.

TABELA 2 - Produção média de massa seca por plântulas de Schizolobium parahyba (Vellozo) Blake com sete semanas desenvolvidas nos substratos areia fina e solo em casa de vegetação no ano de 2004, Curitiba-PR.

\begin{tabular}{|c|c|c|c|c|c|}
\hline \multirow[t]{2}{*}{ Substrato } & \multicolumn{4}{|c|}{ Massa seca média (g planta $\left.{ }^{-1}\right)$. } & \multirow[t]{2}{*}{ Raiz/ Parte aérea } \\
\hline & Raiz & Cotilédone & Parte aérea & Total & \\
\hline & $1,5116( \pm 0,05)$ & $1,4528( \pm 0,08)$ & $1,9478( \pm 0,12)$ & $4,9122( \pm 0,20)$ & $0,7761( \pm 0,02)$ \\
\hline Areia fina & $\frac{b}{3,0034( \pm 0,22)}$ & $\frac{a}{1,2384( \pm 0,07)}$ & $\frac{b}{6,0228( \pm 0,31)}$ & $\begin{array}{c}b \\
10,2646( \pm 0,50)\end{array}$ & $\frac{a}{0,4987( \pm 0,02)}$ \\
\hline Solo & a & a & a & a & $\mathrm{b}$ \\
\hline
\end{tabular}

de probabilidade. Valores entre parênteses representam o erro padrão da média.

A Tabela 3 apresenta os teores de macro e micronutrientes encontrados nas raízes e na parte aérea de plântulas de guapuruvu submetidas aos tratamentos areia fina e solo. Os resultados das análises químicas servem, no presente trabalho, para caracterizar a espécie estudada, sendo a ênfase da discussão neste particular, a comparação entre os teores dos elementos com outras espécies florestais, considerando que para a avaliação do estado nutricional das plantas utilizam-se como valores de referência os teores foliares (CARNEIRO et al., 2006). Os teores encontrados na parte aérea no substrato areia fina em ordem decrescente foram: $\mathrm{N}>\mathrm{K}>\mathrm{P}>\mathrm{Ca}>\mathrm{Mg}>\mathrm{Fe}>\mathrm{Cu}>\mathrm{Mn}>\mathrm{Zn}$. No substrato solo, para a parte aérea obteve-se: $\mathrm{N}>\mathrm{K}>\mathrm{Ca}>\mathrm{P}>\mathrm{Mg}>\mathrm{Fe}>\mathrm{Mn}>\mathrm{Cu}>\mathrm{Zn}$. Cabe lembrar que estes teores estão sujeitos ao efeito de diluição ou concentração. Assim, considerando a parte aérea, pode-se verificar que os elementos $\mathrm{N}, \mathrm{Ca}, \mathrm{Mg}$ e $\mathrm{Mn}$ não ficaram submetidos ao efeito de diluição ou concentração (Tabelas 3 e 5). Os valores de $\mathrm{Fe}$ $\left(257,22 \mathrm{mg} \mathrm{kg}^{-1}\right)$ e $\mathrm{Zn}\left(223,37 \mathrm{mg} \mathrm{kg}^{-1}\right)$ para o compartimento radicular, no substrato areia fina, possivelmente devem ser explicados devido a uma possível contaminação do substrato, o qual não era quartzo puro.

Em solução nutritiva, MARQUES et al. (2004), estudando mudas de paricá (Schizolobium amazonicum) obtiveram teores foliares equivalentes a seguinte ordem decrescente: $\mathrm{Ca}(25,48 \mathrm{~g}$ $\left.\mathrm{kg}^{-1}\right) ; \mathrm{N}\left(18,86 \mathrm{~g} \mathrm{~kg}^{-1}\right) ; \mathrm{K}\left(13,56 \mathrm{~g} \mathrm{~kg}^{-1}\right) ; \mathrm{P}\left(4,23 \mathrm{~g} \mathrm{~kg}^{-1}\right)$; $\operatorname{Mg}\left(3,16 \mathrm{~g} \mathrm{~kg}^{-1}\right) ; \mathrm{Fe}\left(339,16 \mathrm{mg} \mathrm{kg}^{-1}\right) ; \mathrm{Mn}(54,63 \mathrm{mg}$ $\left.\mathrm{kg}^{-1}\right)$; Zn $\left(47,56 \mathrm{mg} \mathrm{kg}^{-1}\right)$ e Cu $\left(6,74 \mathrm{mg} \mathrm{kg}^{-1}\right)$. 
SEREDA, F. et al. Aspectos nutricionais de sementes e plântulas...

TABELA 3 - Teores médios de macro e micronutrientes, na raiz e na parte aérea de plântulas de Schizolobium parahyba (Vellozo) Blake com sete semanas desenvolvidas nos substratos areia fina e solo em casa de vegetação no ano de 2004, Curitiba-PR.

\begin{tabular}{|c|c|c|c|c|c|}
\hline \multicolumn{2}{|c|}{ Nutriente } & \multicolumn{2}{|c|}{ Raiz } & \multicolumn{2}{|c|}{ Parte aérea } \\
\hline $\mathrm{N}$ & \multirow{5}{*}{$\left(\mathrm{g} \mathrm{kg}^{-1}\right)$} & 51,82 & 40,35 & 46.08 & 57.47 \\
\hline$P$ & & 10,93 & 6,57 & 5,61 & 3,13 \\
\hline $\mathrm{K}$ & & 23,52 & 8,82 & 19,20 & 9,92 \\
\hline $\mathrm{Ca}$ & & 1,68 & 3,04 & 1,38 & 4,94 \\
\hline $\mathrm{Mg}$ & & 1,48 & 2,88 & 1,30 & 1,80 \\
\hline $\mathrm{Fe}$ & \multirow{4}{*}{$\left(\mathrm{mg} \mathrm{kg}^{-1}\right)$} & 257,22 & 695,94 & 55,09 & 59,51 \\
\hline $\mathrm{Mn}$ & & 15,38 & 50,99 & 24,95 & 33,32 \\
\hline $\mathrm{Cu}$ & & 20,25 & 9,48 & 53,03 & 26,43 \\
\hline $\mathrm{Zn}$ & & 223,37 & 30,66 & 16,91 & 9,89 \\
\hline
\end{tabular}

KNAPIK e ANGELO (2007) avaliando a resposta de mudas de pessegueiro-bravo (Prunus sellowii) à adubação com NPK em substrato à base de casaca de Pinus sp. e vermiculita, encontraram a seguinte ordem decrescente para o tratamento testemunha nas folhas: $\mathrm{Ca}\left(16,0 \mathrm{~g} \mathrm{~kg}^{-1}\right) ; \mathrm{K}(14,1 \mathrm{~g}$ $\left.\mathrm{kg}^{-1}\right) ; \mathrm{N}\left(13,9 \mathrm{~g} \mathrm{~kg}^{-1}\right) ; \mathrm{Mg}\left(4,3 \mathrm{~g} \mathrm{~kg}^{-1}\right) ; \mathrm{P}\left(1,7 \mathrm{~g} \mathrm{~kg}^{-1}\right) ; \mathrm{Mn}$ $\left(987 \mathrm{mg} \mathrm{kg}^{-1}\right)$; Fe $\left(247 \mathrm{mg} \mathrm{kg}^{-1}\right) ; \mathrm{Zn}\left(40 \mathrm{mg} \mathrm{kg}^{-1}\right)$ e Cu (15,5 $\left.\mathrm{mg} \mathrm{kg}^{-1}\right)$. Já THIBES-RODRIGUES et al. (2006) em mudas de branquilho (Sebastiana commersoniana) cultivadas em solo não contaminado por petróleo e adubado, obtiveram teores foliares da seguinte ordem decrescente: $P$ $\left(15,8 \mathrm{~g} \mathrm{~kg}^{-1}\right) ; \mathrm{N}\left(13,15 \mathrm{~g} \mathrm{~kg}^{-1}\right) ; \mathrm{Ca}\left(10,1 \mathrm{~g} \mathrm{~kg}^{-1}\right) ; \mathrm{K}(7,65$ $\left.\mathrm{g} \mathrm{kg}^{-1}\right) \mathrm{Mg}\left(1,78 \mathrm{~g} \mathrm{~kg}^{-1}\right) ; \mathrm{Mn}$ (436 mg kg-1); Fe (317 mg $\left.\mathrm{kg}^{-1}\right)$ e $\mathrm{Zn}\left(223,5 \mathrm{mg} \mathrm{kg}^{-1}\right)$.

Diferente do resultado desse trabalho, as citações apresentadas acima chamam atenção pelo fato do teor de $\mathrm{N}$ não ocupar a primeira posição, em comparação ao observado no presente estudo (Tabela 3), tendo em vista que é normalmente o elemento de maior concentração em tecidos foliares.
$\mathrm{Na}$ Tabela 4 é apresentado o teste comparativo dos conteúdos totais encontrados nos compartimentos analisados nas plântulas, em areia fina e solo, com a reserva inicial da semente, para macro e micronutrientes. Verifica-se que em relação às reservas inicial da semente a ordem decrescente do conteúdo dos nutrientes analisados foi: $\mathrm{N}>\mathrm{K}>\mathrm{P}>\mathrm{Ca}>\mathrm{Mg}>\mathrm{Zn}>\mathrm{Fe}>\mathrm{Mn}>\mathrm{Cu}$. Supõe-se que $\mathrm{O}$ principal composto armazenado em sementes de guapuruvu são as proteínas devido à quantidade de $\mathrm{N}$ armazenada em suas reservas. No presente caso, este teor de $\mathrm{N}$ seria equivalente a $452 \mathrm{~g} \mathrm{~kg}^{-1}$ de proteína bruta, considerando que a maioria das proteínas contém nas suas moléculas aproximadamente $162 \mathrm{~g} \mathrm{~kg}^{-1}$ de $\mathrm{N}$ (NOGUEIRA e SOUZA, 2005). Segundo FERREIRA e BORGHETTI (2004), sementes que acumulam proteínas apresentam funções importantes tanto para a semente como para o desenvolvimento das plântulas, como de reserva, estrutural e metabólica, de proteção e, em alguns casos, ocorre uma combinação de funções.

TABELA 4 - Comparação entre o conteúdo médio total de plântulas de Schizolobium parahyba (Vellozo) Blake desenvolvidas nos substratos areia fina e solo e a reserva inicial total da semente no ano de 2004,Curitiba-PR.

\begin{tabular}{|c|c|c|c|c|}
\hline \multicolumn{2}{|c|}{ Conteúdo } & Areia fina* & Solo* & Reserva inicial total da semente \\
\hline $\mathrm{K}$ & $\left(\mathrm{mg} \mathrm{planta}^{-1}\right)$ & $11,68( \pm 0,28) a$ & $11,33( \pm 0,27) a$ & $9,62( \pm 0,13) b$ \\
\hline $\mathrm{Mg}$ & & $1,40( \pm 0,06) b$ & $3,09( \pm 0,15) a$ & $2,02( \pm 0,23) b$ \\
\hline $\mathrm{Fe}$ & & $60,00( \pm 2,75) b$ & $278,83( \pm 2,39) a$ & $12,73( \pm 0,39) \mathrm{c}$ \\
\hline $\mathrm{Mn}$ & (ug nlanta ${ }^{-1}$ ) & $14,67( \pm 0,80) b$ & $49,48( \pm 2,00) a$ & $10,63( \pm 0,22) b$ \\
\hline
\end{tabular}
seguidas pela mesma letra nas linhas não diferem estatisticamente entre si pelo teste de Tukey ao nível de $5 \%$ de probabilidade. Valores entre parênteses representam o erro padrão da média.

Os nutrientes N, Ca, Mg e Mn (Tabela 4) não diferiram estatisticamente pelo teste de Tukey ao nível de $5 \%$ de probabilidade entre o substrato areia fina $\left(27,83 ; 1,40,1,74\right.$ e $14,67 \mathrm{mg} \mathrm{planta}^{-1}$, respectivamente) e as reservas iniciais da semente $\left(25,80 ; 2,02,2,81\right.$ e $10,63 \mathrm{mg}$ semente $^{-1}$, respectivamente), ou seja, durante sete semanas, plântulas submetidas ao tratamento com areia fina possivelmente utilizaram as reservas da semente como única fonte nutricional para o seu desenvolvimento.

Com relação aos micronutrientes (Tabela 4) podem-se destacar os valores de $\mathrm{Fe}$ e $\mathrm{Mn}$ no substrato solo $\left(278,83\right.$ e 49,48 $\mathrm{mg}_{\text {planta-1 }}{ }^{-1} \mathrm{em}$ comparação a areia fina e reserva total das sementes. Parece ter ocorrido contribuição do solo para o desenvolvimento das plântulas submetidas a esse substrato. Outro aspecto relevante em relação 
aos valores de $\mathrm{Fe}$ e $\mathrm{Zn}$ em areia fina $(60,00$ e 56,46 mg planta ${ }^{-1}$, respectivamente), cujo conteúdo encontrado foi superior ao da reserva inicial da semente $\left(12,73\right.$ e 17,57 mg semente ${ }^{-1}$, respectivamente). Provavelmente, devido a areia utilizada no experimento não ser de quartzo puro, possivelmente apresentando minerais como a biotita. É importante lembrar que essa areia foi tratada com ácido clorídrico a $1,5 \mathrm{~mol} \mathrm{~L}^{-1}$, podendo também auxiliar a intemperização de alguns minerais, e contribuir na liberação desses elementos. Somado a isso, as plântulas desnutridas podem ter liberado ácidos orgânicos como uma estratégia de contornar esta situação de desnutrição (MARSCHNER, 1995) ou mesmo, uma eventual contaminação do substrato. Os valores de $\mathrm{N}$ apresentados na Tabela 5 variaram entre 6,82 e $38,10 \mathrm{mg} \mathrm{planta}^{-1}$, com destaque para a parte aérea $\left(38,10 \mathrm{mg} \mathrm{planta}^{-1}\right)$ seguido da raiz $\left(13,00 \mathrm{mg}\right.$ planta $\left.{ }^{-1}\right)$, relacionados ao substrato solo. Sob o ponto de vista de quantidade, ocorre uma diferença expressiva em relação aos demais nutrientes avaliados. O N é o elemento de maior exigência pelas plantas, sendo constituinte de diversos componentes da célula vegetal (TAIZ e ZEIGER, 2006).

TABELA 5 - Conteúdo médio de macronutrientes e micronutrientes em diferentes compartimentos de plântulas de Schizolobium parahyba (Vellozo) Blake com sete semanas desenvolvidas nos substratos areia fina e solo em casa de vegetação no ano de 2004, Curitiba-PR.

\begin{tabular}{|c|c|c|c|c|c|c|c|}
\hline \multirow{2}{*}{\multicolumn{2}{|c|}{ Conteúdo }} & \multicolumn{2}{|c|}{ Raiz } & \multicolumn{2}{|c|}{ Cotilédone } & \multicolumn{2}{|c|}{ Parte Aérea } \\
\hline & & Areia fina & Solo & Areia fina & Solo & Areia fina & Solo \\
\hline & & $8,67( \pm 0,16)$ & $13,00( \pm 0,43)$ & $9,30( \pm 0,63)$ & $6,82( \pm 0,65)$ & $9,86( \pm 0,31)$ & $38,10( \pm 1,66)$ \\
\hline $\mathrm{N}$ & & b & $a$ & a & $\mathrm{b}$ & $\mathrm{b}$ & $a$ \\
\hline & & $1,83( \pm 0,04)$ & $2,15( \pm 0,04)$ & $1,94( \pm 0,10)$ & $1,48( \pm 0,10)$ & $1,20( \pm 0,05)$ & $2,07( \pm 0,04)$ \\
\hline $\mathrm{P}$ & & b & a & a & $\mathrm{b}$ & b & a \\
\hline & $\left(\mathrm{mg} \mathrm{planta}^{-1}\right)$ & $3,92( \pm 0,20)$ & $2,88( \pm 0,04)$ & $3,63( \pm 0,24)$ & $1,87( \pm 0,30)$ & $4,13( \pm 0,19)$ & $6,58( \pm 0,23)$ \\
\hline $\mathrm{K}$ & Y pranta & $\begin{array}{c}a \\
0,28( \pm 0,01)\end{array}$ & $\begin{array}{c}b \\
1,01( \pm 0,06)\end{array}$ & $\begin{array}{c}a \\
1,16 \stackrel{( \pm 0,07)}{ }\end{array}$ & $\begin{array}{c}b \\
2,03( \pm 0,15)\end{array}$ & $\begin{array}{c}\mathrm{b} \\
0,30( \pm 0,02)\end{array}$ & $\begin{array}{c}a \\
3,32( \pm 0,33)\end{array}$ \\
\hline $\mathrm{Ca}$ & & b & a & b & a & b & a \\
\hline & & $0,24( \pm 0,01)$ & $0,94( \pm 0,05)$ & $0,88( \pm 0,05)$ & $0,94( \pm 0,05)$ & $0,28( \pm 0,02)$ & $1,21( \pm 0,12)$ \\
\hline $\mathrm{Mg}$ & & $\mathrm{b}$ & $a$ & $a$ & $a$ & $\mathrm{~b}$ & $a$ \\
\hline & & $43,15( \pm 3,47)$ & $222,23( \pm 16,90)$ & $5,13( \pm 0,67)$ & $16,60( \pm 2,76)$ & $11,73( \pm 1,29)$ & $40,00( \pm 6,32)$ \\
\hline $\mathrm{Fe}$ & & b & a & b & a & b & a \\
\hline & & $2,58( \pm 0,20)$ & $16,55( \pm 1,55)$ & $6,73( \pm 0,64)$ & $10,85( \pm 0,85)$ & $5,36( \pm 0,47)$ & $22,09( \pm 1,89)$ \\
\hline $\mathrm{Mn}$ & $\left(\right.$ ug planta $\left.{ }^{-1}\right)$ & b & $a$ & $\mathrm{~b}$ & $a$ & b & $a$ \\
\hline & & $3,39( \pm 0,09)$ & $3,15( \pm 0,21)$ & $3,56( \pm 0,80)$ & $3,38( \pm 0,13)$ & $3,65( \pm 0,19)$ & $6,60( \pm 0,50)$ \\
\hline $\mathrm{Cu}$ & & $a$ & $a$ & $a$ & a & b & a \\
\hline & & $37,26( \pm 3,30)$ & $10,17( \pm 0,75)$ & $7,71( \pm 0,51)$ & $4,76( \pm 0,52)$ & $11,49( \pm 1,06)$ & $17,44( \pm 1,46)$ \\
\hline $\mathrm{Zn}$ & & $a$ & $\mathrm{~b}$ & $a$ & $\mathrm{~b}$ & $\mathrm{~b}$ & a \\
\hline
\end{tabular}

As médias seguidas pela mesma letra nas linhas (dentro de cada compartimento) não diferem estatisticamente entre si pelo teste de Tukey ao nível de $5 \%$ de probabilidade. Valores entre parênteses representam o erro padrão da média.

Ao contrário do $\mathrm{N}$ que se demonstrou superior para a parte aérea, o $\mathrm{P}$ foi expressivo no sistema radicular $\left(2,15 \mathrm{mg}_{\text {planta-1 }}\right)$ onde ocorreu uma melhor alocação dos cotilédones para as raízes, bem como, melhor absorção do solo ficando possivelmente na forma complexada nas plântulas desenvolvidas no substrato solo. Os ânions fosfato competem com a planta em relação aos elementos $\mathrm{Fe}$ e $\mathrm{Mn}$, interferindo tanto na absorção quanto no transporte interno do nutriente (MENGEL e KIRKBY, 1987). Esse fato foi observado por BATTY et al. (2002) e PÉCSVÁRADI et al. (2005), os quais observaram que o $P$ permaneceu imobilizado na superfície radicular e no apoplasto sob a forma de complexos com os ânions $\mathrm{Fe}, \mathrm{Mn}$ e Al.

$\mathrm{O} \mathrm{K}$ foi o segundo nutriente em termos de quantidade, variando entre 1,87 e $6,58 \mathrm{mg}_{\text {planta- }}{ }^{-1}$ no experimento e mantendo a mesma proporção do $\mathrm{N}$ em todos os compartimentos analisados (Tabela 5). Este fato concorda com MALAVOLTA (2004), sobre a importância da relação $\mathrm{N} / \mathrm{K}$, o qual afirma que é comum o $\mathrm{K}$ acompanhar o $\mathrm{N}$ para as regiões dreno na planta. Os valores para $\mathrm{K}$ foram crescentes da raiz $\left(\right.$ areia fina $=3,92 \mathrm{mg}$ planta $^{-1}$ e solo $=2,88 \mathrm{mg}$ planta $^{-1}$ ) para a parte aérea (areia fina $=4,13 \mathrm{mg}$ planta $^{-1}$ e solo $=6,58 \mathrm{mg}$ planta $\left.{ }^{-1}\right)$.

Com relação aos macronutrientes secundários, determinadas espécies utilizam o $\mathrm{Ca}$ para formar cristais de oxalato e, em muitos casos, não são imobilizados durante a germinação (LOTT et al., 1982). Esse fato explica o comportamento diferenciado do $\mathrm{Ca}$ (areia fina $=1,16 \mathrm{mg}_{\text {planta- }}{ }^{-1} \mathrm{e}$ solo $=2,03 \mathrm{mg} \mathrm{planta}^{-1}$ ) em relação ao $\mathrm{Mg}$ (areia fina $=0,88 \mathrm{mg}_{\text {planta }}{ }^{-1}$ e solo $=0,94 \mathrm{mg}_{\text {planta }}{ }^{-1}$ ), no compartimento cotilédone. Com a ausência do Ca no substrato areia fina, houve uma maior mobilização desse nutriente dos cotilédones $(1,16$ mg planta $\left.{ }^{-1}\right)$ para os drenos raiz e parte aérea das plântulas. O contrário foi observado no substrato solo $\left(2,03 \mathrm{mg}\right.$ planta- $\left.{ }^{-1}\right)$, no qual plântulas submetidas a esse tratamento aproveitaram melhor as condições do próprio substrato utilizando o Ca disponível. Devido a esse aspecto formas possivelmente complexadas encontradas nos cotilédones foram pouco utilizadas pelas plântulas, refletindo em valores superiores para esse compartimento. Segundo TOMAZ et al. (2003) mecanismos de ordem fisiológica e genética, estão envolvidos na capacidade de retranslocação interna de $\mathrm{Ca}$ compartimentalizado. Esses mecanismos podem resultar na inativação ou mobilização desse nutriente em membranas e órgãos celulares de armazenamento.

Referente aos micronutrientes, o conteúdo de $\mathrm{Fe}$ variou entre 5,13 ug planta $^{-1}$ no 
SEREDA, F. et al. Aspectos nutricionais de sementes e plântulas...

cotilédone no substrato areia fina e 222,23 ug planta $^{-1}$ na raiz no solo. Os menores valores foram encontrados no compartimento cotilédone (areia fina $=5,13$ e solo $=16,60$ ug planta $^{-1}$ ). O Mn variou entre 2,58 e 22,09 ug planta ${ }^{-1}$, sendo que os maiores conteúdos foram encontrados na parte aérea seguida da raiz e do cotilédone no substrato solo $\left(22,09 ; 16,55\right.$ e 10,85 ug planta $^{-1}$, respectivamente). O Zn alcançou 4,76 ug planta-1 no cotilédone no solo e, os maiores valores ficaram em 37,26 ug planta $^{-1}$ na raiz em areia fina.

Segundo KIGEL e GALILI (2004), certos elementos podem ser fixados em determinadas células, enquanto outros podem aparecer localizados de forma aleatória. De acordo com esses autores, em várias sementes traços de elementos como $\mathrm{Fe}, \mathrm{Zn}$ e $\mathrm{Mn}$ são encontrados em cristais globoides em certas células do embrião, porém isso não é regra. A forma como ocorre o armazenamento desses e outros elementos não está esclarecida.

Com relação ao $\mathrm{Cu}$ o maior conteúdo foi encontrado na parte aérea em solo seguido de areia fina $\left(6,60\right.$ e 3,65 ug planta $^{-1}$, respectivamente) concordando com o descrito por MENGEL e KIRKBY (1987), os quais citam que, grande parte desse elemento encontra-se nas folhas.

Conforme discutido acima, é importante citar que, além do conteúdo das reservas, torna-se importante o meio em que as plântulas, como o guapuruvu, vão se desenvolver. O fornecimento nutricional dado pelas reservas durante a fase de estabelecimento e, a disponibilidade de nutrientes no substrato proporciona a manutenção da população desta espécie em ambientes naturais.

\section{CONCLUSÕES}

1) Plântulas de guapuruvu desenvolvidas em solo produziram maior quantidade de massa seca nos compartimentos raiz e parte aérea, em comparação àquelas que cresceram em areia fina.

2) Teores de nutrientes encontrados em plântulas de guapuruvu variaram em função do substrato utilizado para germinação e seguiram a seguinte ordem decrescente em areia fina: $\mathrm{N}>\mathrm{K}>\mathrm{P}>\mathrm{Ca}>\mathrm{Mg}>\mathrm{Fe}>\mathrm{Cu}>\mathrm{Mn}>\mathrm{Zn}$ e em solo: $\mathrm{N}>\mathrm{K}>\mathrm{Ca}>\mathrm{P}>\mathrm{Mg}>\mathrm{Fe}>\mathrm{Mn}>\mathrm{Cu}>\mathrm{Zn}$.

3) Foram encontrados nas reservas de sementes de guapuruvu, o seguinte conteúdo de em ordem decrescente: $\mathrm{N}>\mathrm{K}>\mathrm{P}>\mathrm{Ca}>\mathrm{Mg}>\mathrm{Zn}>$ $\mathrm{Fe}>\mathrm{Mn}>\mathrm{Cu}$.

\section{AGRADECIMENTOS}

Ao CNPq, pela concessão da bolsa de iniciação científica a Fernanda Sereda, durante a realização desta pesquisa. Ao Projeto Solobioma, aos funcionários da Sociedade de Pesquisa em Vida Selvagem e Educação Ambiental (SPVS) que ajudaram neste estudo e ao Pesquisador Edílson Batista de Oliveira (EMBRAPA FLORESTAS) pelas valiosas sugestões.

\section{REFERÊNCIAS}

1. AZEVEDO, G. A.; BRUNO, R. L. A.; ANDRADE, L. A.; CUNHA, A. O. Germinação em sementes de espécies florestais da Mata Attântica (Leguminoseae) sob condições de casa de vegetação. Pesquisa Agropecuária Tropical, v. 33, n. 1, p. 11-16, 2003.

2. BATTY, L. C.; BAKER, A. J. M.; WHEELER, B. D. Aluminium and phosphate uptake by Phragmites australis: the role of Fe, Mn and Al root plaques. Annals of Botany, v. 84, n. 4, p. 443-449, 2002.

3. BRAGA, F. A. M.; VALE, F. R.; VENTURIM, N.; AUBERT, E.; LOPES, G. A.. Exigências nutricionais de quatro espécies florestais. Revista Árvore, v. 19, n. 1, p. 18-31, 1995.

4. CARNEIRO, C.; REISSMANN, C. B.; MARQUES, R. Comparação de métodos de análise química de K, Ca, Mg e Al, em folhas de erva-mate (Ilex paraguariensis St. Hil.). Cerne, v. 12, n. 2, p. 113-122, 2006.

5. FERREIRA, A. G.; BORGHETTI, F. Germinação: do básico ao aplicado. Porto Alegre: Artmed, 2004. 323 p.

6. GALVÃO, A. P. M.; MEDEIROS, A. C. de S. Restauração da Mata Atlântica em áreas de sua primitiva ocorrência natural. Colombo: Embrapa Florestas, 2002, 133 p.

7. KIGEL, J.; GALILI, G. Seed development and germination. New York: Marcel Dekker, 2004. $853 p$

8. KNAPIK, J. G.; ANGELO, A. C. Crescimento de mudas de Prunus sellowii Koehne em resposta a adubações com NPK e pó de basalto. Floresta, v. 17, n. 2, p. 257-264, 2007.

9. LOTT, J. N. A.; GRENWOOD, J. S.; VOLLMER, C. M. Mineral reserves in castor beans: the dry seed. Plant Physiology, v. 69 , p. 829-833, 1982.

10. LOTT, J. N. A.; OCKENDEN, I.; RABOY, V.; BATTEN, G. D. Phytic acid and phosphorus in crop seeds and fruits: a global estimate. Seed Science Research, v. 10. p. 11-33, 2000.

11. LOTT, J. N. A.; SPITZER. X-Ray analysis studies of elements stored in protein body globoid crystals of Triticum grains. Plant Physiology, v. 66, p. 494-499, 1980.

12. MALAVOLTA, E. Potássio: absorção, transporte e redistribuição na planta. Informações Agronômicas, n. 108, p. 116, 2004.

13. MARSCHNER, H. Mineral nutrition of higher plants. 2 ed. London: Academic Press, 1995. 889 p.

14. MARQUES, T. C. L. L. de S. M.; de CARVALHO, J. G.; LACERDA, M. P. C.; da MOTA, P. E. F. Exigências nutricionais do paricá (Schizilobium amazonicum, Herb.) na fase de muda. Cerne, v. 10, n. 2, p. 167-183, 2004.

15. MARTINS, A. P. L.; REISSMANN, C.B. Material vegetal e as rotinas laboratoriais nos procedimentos químico-analíticos. Scientia Agraria, v. 8, n. 1. p. 1-17, 2007.

16. MENGEL, K.; KIRKBY, E. A. Principles of plant nutrition. Bern: International Potash Institute, 1987. $687 \mathrm{p.}$

17. NICOLOSO, F. T.; ZANCHETTI, F.; GARLET, A.; FOGAÇA, M. A. de F. Exigências nutricionais de grápia (Apuleia leiocarpa Vog. Macbride) em solo podzólico vermelho amarelo. Ciência Rural, v. 29, n. 2, p. 225-231, 1999.

18. NOGUEIRA, A. R de A.; SOUZA, G. B. Manual de laboratórios: solo, água, nutrição vegetal, nutrição animal e alimentos. São Carlos: Embrapa Pecuária Sudeste, 2005. 334 p. 
SEREDA, F. et al. Aspectos nutricionais de sementes e plântulas...

19. PÉCSVÁRADI, A.; VASHEGYI, A.; HADÁR, E.; VARGA, B. BONA,L.; ZSOLDOS, F. Response of rice seedlings to aluminium stress with varying phosphate supplies. Acta Biologica Szegediensis, v. 49, n. 1-2. p. 107-109, 2005.

20. STASOVSKI, E; PETERSON, C. A. The effects of drought and subsequent rehydration on the structure and vitality of Zea mays seedling roots. Canadian Journal of Botany, v. 69, n. 6, p. 1170-1178, 1991.

21. TAIZ, L.; ZEIGER, E. Fisiologia vegetal. 3.ed. Porto Alegre: Artmed, 2006. 719 p.

22. THIBES-RODRIGUES, T.; WISNIEWSKI, C.; BONA, C.; DEDECEK, R. A.; SANTOS, G. O. Caracterização nutricional de branquilho (Sebastiana commersoniana (Baillon) Smith \& Downs - Euphorbiaceae), cultivado em solo contaminado por petróleo. Floresta, v. 36, n. 3, p. 349- 359, 2006.

23. TOMAZ, M. A.; SILVA, S. R.; SAKIYAMA, N. S.; MARTINEZ, H. E. P. Eficiência de absorção, translocação e uso de cálcio, magnésio e enxofre por mudas enxertadas de Coffea arabica. Revista Brasileira de Ciência do Solo, v. 27, p. 885892, 2003.

Recebido em 11/04/2008

Aceito em 19/12/2008 
